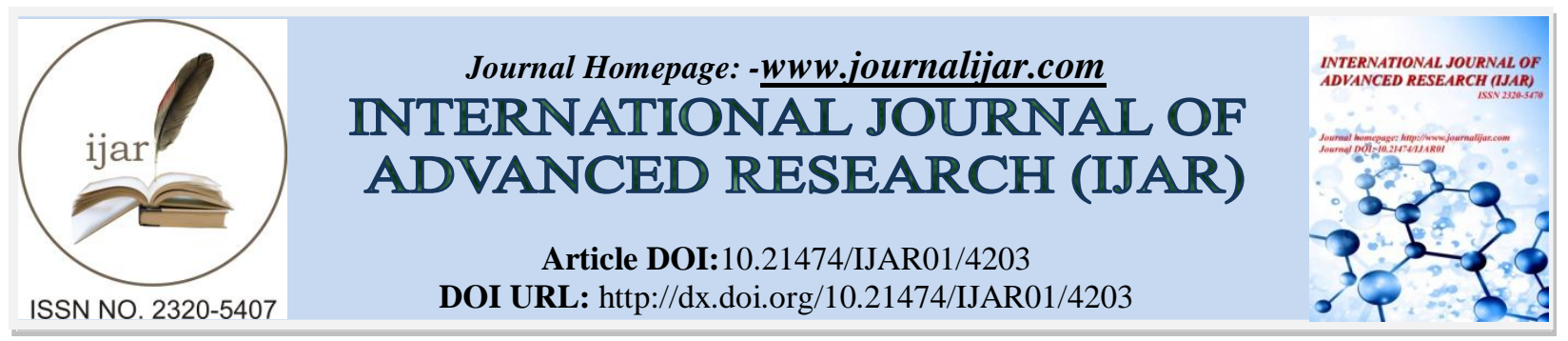

RESEARCH ARTICLE

\title{
CORRELATION BETWEEN THE GENOTYPE DETECTION DETERMINED BY RT- PCR ASSAYS AND THE PHENOTYPIC DETECTION DETERMINED BY ANTIBIOTIC SUSCEPTIBILITY PATTERNS OF METHICILLIN-RESISTANT STAPHYLOCOCCUS AUREUS CLINICALISOLATES IN ALGERIA.
}

\section{*Amina Ayeche ${ }^{1}$, Névine Lebsir ${ }^{2}$ And Mohamed Abdelhafid Hamidechi ${ }^{1}$.}

1. Laboratoire de Biologie Cellulaire et Moléculaire, Faculté des Sciences de la nature et de la vie, Université des frères Mentouri Constantine1, Rue Ain El bey- 25000 Constantine-Algérie.

2. Laboratoire de Microbiologie, Hôpital de pédiatrie d'El-Mansourah, Constantine-Algérie.

\section{Manuscript Info}

Manuscript History

Received: 14 March 2017

Final Accepted: 12 April 2017

Published: May 2017

Key words:-

Staphylococcus aureus, Methicillinresistant Staphylococcus aureus (MRSA), mecA, RT-PCR.

\section{Abstract}

Methicillin-resistant Staphylococcus aureus (MRSA) is a major public health problem causing both hospital and community associated infections worldwide. Methicillin resistance is usually due to the mecA gene that codes for a $78-\mathrm{kD}$ a penicillin binding protein (PBP2a), with decreased affinity to methicillin and all beta-lactam antibiotics. A total of $65 \mathrm{~S}$. aureus isolates were collected from a pediatric hospital and clinical laboratories in Constantine, from December 2014 to September 2015. All isolates were identified using matrix-assisted laser desorption/ionisation time of flight mass spectrometry(MALDITOF-MS). The phenotypic detection of methicillin-resistant was investigated using the standard disk-diffusion method on MuellerHinton agar. The isolates were tested with 16 antibiotics: Penicillin, oxacillin, Cefoxitin, Ceftriaxone, Ciprofloxacin, Gentamicin, Teicoplanin, Vancomycin, Erythromycin, Clindamycin, Pristinamycin, Doxycycline, Fosfomycin, Linezolid, Rifampicin and Trimethoprim-sulfamethoxazole. They were incubated at $37^{\circ} \mathrm{C}$ for 24 h. Results showed that $35.38 \%$ of isolates were methicillinresistantStaphylococcus aureus. According to the obtained results from RT-PCR analysis of methicillin-resistant S. aureus (MRSA), $m e c A$ gene was present in $86.95 \%$ of the resistant isolates. The results of comparison between RT-PCR detection of mecA gene and standard disk diffusion test showed high degree of correlation.

Copy Right, IJAR, 2016,. All rights reserved.

\section{Introduction:-}

Staphylococcus aureus is recognized as one of the most important pathogens responsible for a variety of diseases in both humans and animals worldwide [1,2, 3, 4]. Staphylococcus aureus was first identified in 1880 in Aberdeen, Scotland [2, 5]. Until the treatment of patients with penicillin in $1940[2,5]$, the mortality rate caused byS. aureus was $80 \%$. In 1942, the first strains developed resistance to penicillin, due to $\beta$-lactamase production, were detected in hospital [2]. The introduction of methicillin in 1959 was necessary to solve the problems of penicillinaseproducing $S$. aureus resistant to penicillin [6,7]. Resistance to methicillin in $S$. aureus was identified for the first time in UK in the early $1960[2,8,9,10,11,12,13,14]$, within 2 years after its introduction $[6,7,12]$

Corresponding Author:- Amina Ayeche.

Address:-Laboratoire de Biologie Cellulaire et Moleculaire, Faculté des Sciences de la nature et de la vie, 
Since then, the resistance rate of methicillin-resistant $S$. aureus (MRSA) has gradually increased and become a serious problem in both community and hospital infections worldwide in 1970 [12]. Until the mid-1990s, the majority of MRSA isolates exhibited multiple resistance to several antimicrobial agents including tetracyclines, aminoglycosides, macrolides, lincosamides and fluoroquinolones [5, 12, 15, 16].

Resistance to methicillin in S. aureus is primarily mediated by the production of penicillin binding protein (PBP 2a), an additional penicillin-binding protein with low affinity for beta-lactam antibiotics, encoded by mecA gene [1, 5, 17] which is absent in methicillin susceptible strains. This gene is carried on the SCCmec element [13].

The detection of MRSA has become an important tool in clinical diagnosis for the management and treatment of patients [6,17]. Routine methods used in microbiology laboratories for identification of methicillin resistance in $S$. aureus are based on antibiotic susceptibility disk diffusion agar and dilution [14, 17]. These methods detect only phenotypic expression of methicillin resistance without the presence of the mecA gene [17]. Since phenotypic methods are not discriminating enough and are highly dependent on growth conditions, the use of genetic approach, such as DNA hybridization and PCR, is essential to stop the spread of S. aureus methicillin-resistant and to increase the rapidity and accuracy of their identification and their antibiotics resistance patterns [6].

The aim of this study was therefore to show the prevalence and antibiotic susceptibility of $S$. aureus methicillinresistance isolated from the pediatric hospital and clinical laboratories in Constantine, Algeria, and to compare the degree of correlation between the phenotypic detection of methicillin-resistance in $S$. aureus by standard disk diffusion test with the genotypic detection of $m e c A$ gene by RT- PCR.

\section{Material and Methods:-}

\section{Bacteria isolates:-}

A total of $65 \mathrm{~S}$. aureus strains were isolated from infected patients. The isolates were collected from the pediatric hospital and clinical laboratories in Constantine (Algeria) from December 2014 to September 2015. The isolates were first identified with standard bacteriological technique and biochemical tests using the API system 20E® (biomérieux., Marcy l'Etoile, France).

\section{Identification of S. Aureus:-}

A confirmation of the staphylococcus aureus identification for all the isolates was performed by using matrixassisted laser desorption/ionisation time of flight mass spectrometry (MALDI-TOF-MS). Colonies were deposited directly on the MALDI-TOF target plate (Four spots per isolate) and were covered with $1.5 \mu \mathrm{L}$ of matrix solution (2 points of a-cyano-4-hydroxycinnamic acid $+500 \mathrm{ml}$ of acetonitrite HPLC $+475 \mathrm{ml}$ of distilled water $+25 \mathrm{ml}$ of trifluoracetic-acid). Spots were analyzed using a Bruker Daltonics Microflex (Bremen, Germany). Peptidic spectra were compared with the Bruker database using Biotyper software, version 2.0, and the identification score was noted.

\section{Antibiotic resistance Test:-}

Antibiotic resistance of $S$. aureus isolates was tested using the standard disk-diffusion method on Mueller-Hinton agar according to recommendations of the Antibiotic Committee of the French Society for Microbiology (CA-SFM) [18]. The isolates were tested with sixteen antibiotics: Penicillin $(10 \mu \mathrm{g})$, oxacillin $(5 \mu \mathrm{g})$, Cefoxitin $(30 \mu \mathrm{g})$, Ceftriaxone $(30 \mu \mathrm{g})$, Ciprofloxacin $(5 \mu \mathrm{g})$, Gentamicin $(15 \mu \mathrm{g})$, Teicoplanin $(30 \mu \mathrm{g})$, Vancomycin $(30 \mu \mathrm{g})$, Erythromycin $(15 \mu \mathrm{g})$, Clindamycin $(15 \mu \mathrm{g})$, Pristinamycin $(15 \mu \mathrm{g})$, Doxycycline $(30 \mu \mathrm{g})$, Fosfomycin $(50 \mu \mathrm{g})$, Linezolid $(30 \mu \mathrm{g})$, Rifampicin $(30 \mu \mathrm{g})$, Trimethoprim-sulfamethoxazole $(25 \mu \mathrm{g})$ and were incubated at $37^{\circ} \mathrm{C}$ for 24 h. Antibiotic disks were purchased from Bio-Rad (Marnes-la-Coquette, France).

\section{DNA Extraction:-}

For detection of mecA gene, all DNA samples were extracted with the DNeasy tissue kit (Qiagen, Hilden, Germany) using EZ1 Advanced instrument (Qiagen). One colony of each isolate was mixed with $200 \mu \mathrm{L}$ of extraction buffer. Extracted DNA was eluted in $200 \mu \mathrm{L}$, analysed immediately after extraction and stored at $-20^{\circ} \mathrm{C}$.

\section{Rt-Pcr:-}

Amplification of the methicillin resistance gene mecA was performed using primers as previously described by Strommenger et al. (2003) and Shahraz et al. (2011): forward primer (5'-AAA ATC GAT GGT AAA GGT TGG C$3^{\prime}$ ) and reverse primer (5'-AGT TCT GCA GTA CCG GAT TTG C-3'). Quantitative real-time PCR (CFX96, C1000 
Thermal Cycler, Bio-Rad) was carried out to detect the encoding gene (MecA). The PCR mixture was prepared for each isolate $\left(10 \mu \mathrm{L}\right.$ of Mix Quantitec, $2 \mu \mathrm{L}$ of Probe, $2 \mu \mathrm{L}$ of $\mathrm{H}_{2} \mathrm{O}, 0.5 \mu \mathrm{L}$ of each primer and $5 \mu \mathrm{L}$ of DNA extracted) in accordance with the manufacturer's instructions . S. aureus ATCC 29213 was used as positive control. The experimental run protocol used was as follows: denaturation program $\left(95{ }^{\circ} \mathrm{C}\right.$ for $\left.15 \mathrm{~min}\right)$, amplification and quantification programs repeated 35 times $\left(95^{\circ} \mathrm{C}\right.$ for $30 \mathrm{~s}, 60{ }^{\circ} \mathrm{C}$ for $\left.1 \mathrm{~min}\right)$.

\section{Results:-}

Identification of $S$. Aureus:-

Identification of S.aureus with standard bacteriological technique and biochemical tests using the API was confirmed by the Bruker Daltonics MALDI-TOF.

\section{Antibiotic susceptibility:-}

In this study the specimens of $S$. aureus were mainly obtained from pus samples with a frequency of $81.53 \%$ followed by urine and semen samples with respectively 12.30 and $6.15 \%$.

The results of resistance rate of all the strains to antibiotics testing according to the French CASFM 2015 revealed that the isolates were multidrug resistant. Higher resistance was observed to penicillin G $(70.77 \%$ of the isolates), followed by ceftriaxone $(50.76 \%)$, erythromycin $(46.15 \%)$, oxacillin and ciprofloxacin $(24.61 \%$ each). However, some isolates were resistant to glycopeptides (vancomycin $4.61 \%$ and teicoplanin $9.23 \%$ ). The classification of antibiotic resistance patterns of the isolated $S$. aureus into three groups of resistant, intermediate-resistance and susceptible is given in Table 1. As shown in Table 1, 23 isolates were found to be methicillin-resistant (35.38\%), while the remaining (42) were 37 (56.92\%) methicillin-susceptible and $5(7.69 \%)$ intermediate resistant. The percentage of MRSA was defined as the number of $S$. aureus isolates resistant to cefoxitine divided by the total number of S. aureus isolates. The majority of the MRSA isolates showed resistance to penicillin G (86.95\% of the isolates), ceftriaxone (78.26\%), oxacillin (65.21\%) and erythromycin $(56.52 \%)$. MSSA isolates were also resistant to penicillin G (70.27\%), erythromycin (45.64\%) and ceftriaxone $(40.54 \%)$. They were highly susceptible to gentamicin (100\%), oxacillin and vancomycin (97.3\% each).

\section{RT-PCR:-}

Real-time PCR results showed that 21 out of 65 S. aureusisolates were positive for the MecA gene as shown in figure 1. Comparison of the results of the MRSA pattern obtained from PCR with the standard disk-diffusion methods is shown in Table 2. According to RT-PCR results, 20 of 23 MRSA strains, 0 of 5 intermediate and 1 of 37 methicillin-succeptible, carried a $M e c A$ gene.

\section{Discussion:-}

Methicillin-resistant $S$. aureusis an important human pathogen and is responsible for both hospital and community associated infections worldwide. Its frequency in most African countries has not been reported [19].

Between 1996 and 1997, the prevalence of MRSA was determined in eight northern African countries and Malta, it was relatively high in Nigeria, Kenya, and Cameroon (21 to 30\%) and below 10\% in Tunisia, Malta and Algeria [19]. In 2001, the resistance rate increased to $14 \%$ in Algeria [9]. Prospective, multicentre study was conducted between 2003 and 2004 with participation of nine university hospitals in the Mediterranean area, and the percentage of S. aureus strains resistant to methicillin (MRSA) was 35.5\% in Algeria [20].

In our study, among $65 S$.aureus isolates 23 were MRSA (35.38\%). These results showed a high similarity with results obtained by previous studies in Algeria.

Resistance of MRSA to other antibiotics has also been reported. In this study, we found that $8.69 \%$ of isolates were resistant to vancomycin, while in related studies; all MRSA strains isolated from clinical samples were susceptible to vancomycin $(100 \%)$ [17, 19]. Shahraz et al. (2012) reported that $26.6 \%$ of S. aureus strains isolated from packaged hamburger were resistant to vancomycin.

According to our study, MRSA were resistant to erythromycin (56.52\%) and gentamycin (34.78\%), RamdaniBouguessa et al. 2005 reported that $25 \%$ and $7 \%$ of PVL-positive MRSA strains isolated from Mustapha Pacha hospital in Algeria and Ouchenane et al. 2010 reported that 25\% and 6.25\% of MRSA strains isolated from 
Didouche Mourad hospital in Algeria, were resistant to erythromycin and gentamicin, respectively. Comparison between these results showed a high resistance to erythromycin and gentamycin in our isolates.

In recent years, several studies have demonstrated the high capacity of molecular methods such as Pulsed-field gel electrophoresis (PFGE), RT-PCR and PCR-based methods to increase the rapidity and accuracy of resistance testing $[1,6,14,15,16,21,22]$.

In our study, molecular detection of $m e c A$ gene as a specific target of MRSA genes was performed for all $65 S$. aureus isolates. As shown in Table 2, we have compared the results of standard disk-diffusion, as a phenotypic method, with real-time PCR, as a genotypic method. Overall, we found high correlation between these two methods. This correlation has been demonstrated previously in other studies $[6,14,15,17]$.

The present study indicate that among 23 strains, 3 were resistant to methicillin and 5 of 65 have intermediateresistance according to standard disk-diffusion method but they are susceptible according to PCR method. Two of 39 strains were methicillin-susceptible according to standard disk-diffusion method but are resistant according to PCR method. In accordance with this study and previous reports, strains that are phenotypically resistant to methicillin but are not carried a mecA gene seemed to show poor expression of mecA gene or production of methicillinase or $\beta$-lactamase hyper-production $[12,16]$. Borderline resistance in mecA-negative strains has been hypothesized, in previous studies, to result from modification of normal PBP genes [8, 23]. Kumar et al., 2010, indicated that mecA gene is present, but is not amplified because the amplification site is not available enough or is not expressed or expressed at low level due to growth conditions or might be limitations in detection in microbiological methods.

Similarly, strains could exhibit intermediate-resistance of methicillin due to overexpression of a b-lactamase when $m e c A$ is absent [24]. Intermediate resistance levels could be due also to mutations in the endogenous mecA gene [6].

In conclusion, the high prevalence of MRSA in Algerian hospitals, as our results showed, is necessary that rapid identification of methicillin-resistance and genotypic detection of mecA gene will have a major impact on the treatment of infectious diseases and to reduce the emergence of drug resistance. Although microbiological susceptibility testing are still widely used in clinical microbiology laboratories for analysis of phenotypic resistance of MRSA, molecular detection of mecA gene with RT-PCR is highly rapid, sensitive and specific. Moreover, all the studies reported to date indicate a high correlation between methicillin-resistance and the presence of the $m e c A$ gene. In this study, comparison between phenotypic detection of methicillin-resistance in $S$. aureus by standard disk diffusion test and genotypic detection of $m e c A$ gene by RT- PCR method showed a high degree of correlation.

Table1: Antibiotic resistance of $S$. aureus strains isolated from infected patients $(\mathrm{n}=65)$.

\begin{tabular}{|c|c|c|c|}
\hline Antibiotic tested & $\begin{array}{c}\text { Nomber of resistant } \\
\text { strains }\end{array}$ & $\begin{array}{l}\text { No. of intermediate- } \\
\text { resistance strains(\%) }\end{array}$ & $\begin{array}{c}\text { No. of susceptible } \\
\text { strains }(\%)\end{array}$ \\
\hline Penicillin & $46(70.77 \%)$ & - & $19(29.23 \%)$ \\
\hline Oxacillin & $16(24.61 \%)$ & - & $49(75.38 \%)$ \\
\hline Cefoxitine & $23(35.38 \%)$ & $5(7.69 \%)$ & $37(56.92 \%)$ \\
\hline Ceftriaxone & $33(50.76 \%)$ & $22(33.84 \%)$ & $10(15.38 \%)$ \\
\hline Ciprofloxacin & $16(24.61 \%)$ & - & $49(75.38 \%)$ \\
\hline Gentamicin & $8(12.30 \%)$ & - & $57(87.69 \%)$ \\
\hline Teicoplanin & $6(9.23 \%)$ & - & $59(90.76 \%)$ \\
\hline Vancomycin & $3(4.61 \%)$ & - & $62(95.38 \%)$ \\
\hline Erythromycin & $30(46.15 \%)$ & - & $35(53.84 \%)$ \\
\hline Clindamycin & $6(9.23 \%)$ & - & $59(90.76 \%)$ \\
\hline Pristinamycin & $3(4.61 \%)$ & - & $62(95.38 \%)$ \\
\hline Doxycycline & $11(16.92 \%)$ & $2(3.07 \%)$ & $52(80 \%)$ \\
\hline Fosfomycin & $5(7.69 \%)$ & - & $60(92.30 \%)$ \\
\hline Linezolid & $3(4.61 \%)$ & - & $62(95.38 \%)$ \\
\hline Rifampicin & $9(13.84 \%)$ & $4(6.15 \%)$ & $52(80 \%)$ \\
\hline $\begin{array}{c}\text { Trimethoprim- } \\
\text { sulfamethoxazole }\end{array}$ & $9(13.84 \%)$ & $1(1.53 \%)$ & $55(84.61 \%)$ \\
\hline
\end{tabular}


Table 2:- Comparison of the results of meticillin-resistant S. aureus (MRSA) pattern obtained from RT-PCR and standard disk-diffusion methods for isolated strains from infected patients $(n=65)$.

\begin{tabular}{|c|c|c|c|}
\hline \multirow[t]{2}{*}{ Method } & \multicolumn{3}{|c|}{ Methicillin-resistance } \\
\hline & $\begin{array}{l}\text { No. of resistant } \\
\text { strains }(\%)\end{array}$ & $\begin{array}{l}\text { No. of intermediate- } \\
\text { resistant strains }(\%)\end{array}$ & $\begin{array}{l}\text { No. of susceptible } \\
\text { strains }(\%)\end{array}$ \\
\hline $\begin{array}{l}\text { Standard disk-diffusion } \\
\text { RT-PCR }\end{array}$ & $\begin{array}{l}23(35.38 \%) \\
20(95.23 \%) \\
\end{array}$ & $\begin{array}{c}5(7.69 \%) \\
-\end{array}$ & $\begin{array}{c}37(56.92 \%) \\
1(4.76 \%)\end{array}$ \\
\hline
\end{tabular}

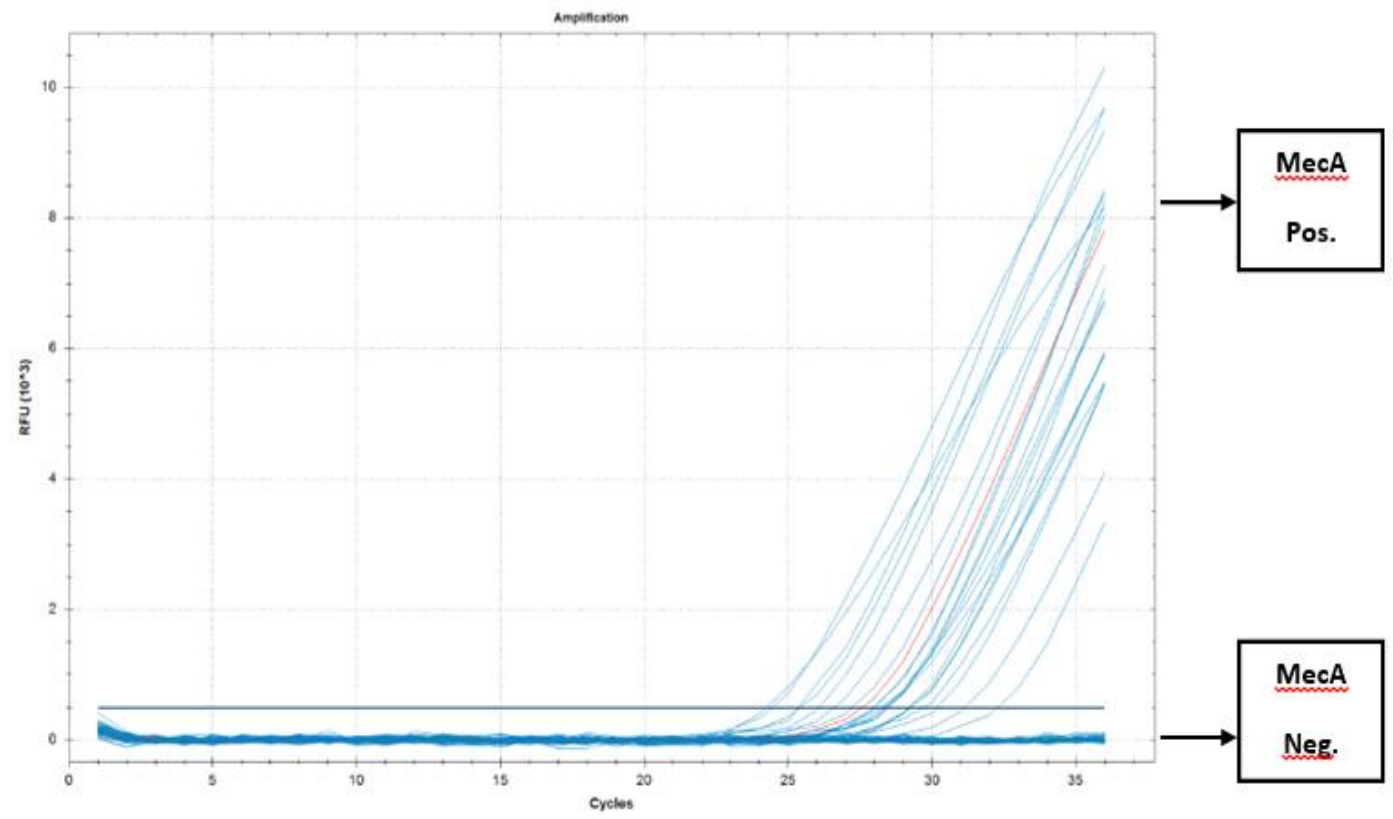

Figure 1:-Representative results obtained in real-time polymerase chain reaction assay for $m e c A$ gene. The amplicon curves, representing positive amplification and negative control (flat line). Pos., positive amplification; neg., negative amplification.

\section{Acknowledgements:-}

We acknowledge the Professor Jean-Marc Rolain (Unité de recherché sur les maladies infectieuses et tropicales émergentes (URMITE), Aix Marseille University, France) for permitting us to perform the experimental part of this work.

\section{References:-}

1. Martineau F, Picard F. J., Lansac N., Ménard C., Roy P. H., Ouellette M. and Bergeron M. J. (2000). Correlation between the Resistance Genotype Determined by Multiplex PCR Assays and the Antibiotic Susceptibility Patterns of Staphylococcus aureus and Staphylococcus epidermidis. Journal of Antimicrobial Agents and Chemotherapy, 44(2):231.

2. Deurenberg R. H., Vink C., Kalenic S., Friedrich A. W., Bruggeman C. A. and Stobberingh E. E. (2007). The molecular evolution of methicillin-resistant Staphylococcus aureus. Clin. Microbiol. Infect., 13:222-235.

3. Kumar R., Yadav B. R. and Singh R. S. (2011). Antibiotic resistance and pathogenicity factors in Staphylococcus aureus isolated from mastitic Sahiwal cattle. J. Biosci., 36(1):175-188.

4. Momtaz H. and Hafezi L. (2014). Meticillin-resistant Staphylococcus aureus isolated from Iranian hospitals: virulence factors and antibiotic resistance properties. Bosn. J. Basic. Med. Sci., 14(4):219-226.

5. Xiaoguang W., Lin O., Lingfei L., Jiqian L., Chiping S., Cuizhen L., Hongjing Y. and Ping W. (2016). Methicillin-resistant staphylococcus aureus isolates in a hospital of Shanghai. www.impactjournals.com/oncotarget.

6. Pe'Rez-Roth E., Claverie-Marti'N F., Villar J. and Me'Ndez-A'Lvarez S. (2001). Multiplex PCR for simultaneous identification of Staphylococcus aureus and detection of methicillin and mupirocin resistance. Journal of Clinical Microbiology, 39(11):4037-4041. 
7. Zhang K., McClure J.-A., Elsayed S., Louie T. and Conly J. M. (2005). Novel Multiplex PCR Assay for Characterization and Concomitant Subtyping of Staphylococcal Cassette Chromosome mec Types I to V in Methicillin-Resistant Staphylococcus aureus. J. Clin. Microbiol., 43(10):5026.

8. Chambers H. F. (1997). Methicillin resistance in Staphylococci: Molecular and Biochemical Basis and Clinical Implications. Clinical Microbiology Reviews, 10(4):781-791.

9. Ramdani-Bouguessa N. Bes M., Meugnier H., Forey F., Reverdy M. E., Lina G., Vandenesch F., Tazir M. and Etienne J. (2006). Detection of Methicillin-Resistant Staphylococcus aureus Strains Resistant to Multiple Antibiotics and Carrying the Panton-Valentine Leukocidin Genes in an Algiers Hospital. Journal of Antimicrobial Agents and Chemotherapy, 50(3):1083-1085.

10. Donnio P.-Y., Preney L., Gautier-Lerestif A.-L., Avril J.-L. and Lafforgue N. (2004). Changes in staphylococcal cassette chromosome type and antibiotic resistance profile in methicillin-resistant Staphylococcus aureus isolates from a French hospital over an 11 year period. Journal of Antimicrobial Chemotherapy, 53(5):808-813.

11. Durand G., Bes M., Meugnier H., Enright M. C., Forey F., Liassine N.,Wenger A., Kikuchi K., Lina G., Vandenesch F. and Etienne J. (2006). Detection of New Methicillin-Resistant Staphylococcus aureus Clones Containing the Toxic Shock Syndrome Toxin 1 Gene Responsible for Hospital- and Community-Acquired Infections in France. Journal of Clinical Microbiology, 44(3):847-853.

12. Moon J.-S., Lee A.-R., Kang H.-M., Lee E.-S., Kim M.-N., Paik Y. H., Park Y. H., Joo Y.-S. and Koo H. C. (2007). Phenotypic and Genetic Antibiogram of Methicillin-Resistant Staphylococci Isolated from Bovine Mastitis in Korea. J. Dairy Sci., 90:1176-1185.

13. Ouchenane Z., Smati S., Rolain J.-M., Raoult D. (2010). Molecular characterization of methicillin-resistant Staphylococcus aureus isolates in Algeria. Journal of Pathologie Biologie, 59:129-132.

14. Shahraz F., Dadkhah H., Khaksar R., Mahmoudzadeh M., Hosseini H., Kamran M. and Bourke P. (2012). Analysis of antibiotic resistance patterns and detection of mecA gene in Staphylococcus aureus isolated from packaged hamburger. Meat Science, 90:759-763.

15. Strommenger B., Kettlitz C., Werner G. and Witte W. (2003). Multiplex PCR assay for simultaneous detection of nine clinically relevant antibiotic resistance genes in Staphylococcus aureus. Journal of Clinical Microbiology, 41(9):4089-4094.

16. Kumar R., Yadav B. R. and Singh R. S. (2010). Genetic Determinants of Antibiotic Resistance in Staphylococcus aureus Isolates from Milk of Mastitic Crossbred Cattle. Curr. Microbiol., 60:379-386.

17. Al-Zu'Bi E., Bdour S. and Shehabi A. A. (2004). Antibiotic resistance patterns of mecA-positive Staphylococcus aureus isolates from clinical specimens and nasal carriage. Microbial Drug ResistanceMechanisms Epidemiology and Disease, 10(4):321-324.

18. CA-SFM, Comité de l'antibiogramme de la Société Française de Microbiologie, 2011, Recommandations 2011, http://www.sfmmicrobiologie.org/UserFiles/file/CASFM/casfm 2011.pdf

19. Kesah C., Ben Redjeb S., Odugbemi T. O., Boye C. S.-B., Dosso M., Ndinya Achola J. O., Koulla-Shiro S., Benbachir M., Rahal K. and Borg M. (2003). Prevalence of methicillin-resistant Staphylococcus aureus in eight African hospitals and Malta. Clin. Microbiol. Infect., 9: 153-156.

20. Amazian K., Fendri C., Missoum M. F. K., Bouzouaia N., Rahal K., Savey A., Saadatian-Elahi M. and Fabry J. (2006). Multicenter pilot survey of resistant bacteria in the Mediterranean area. Eur. J. Clin. Microbiol. Infect. Dis., 25:340-3.

21. Lacey R. W. (1973). Genetic basis, epidemiology, and future significance of antibiotic resistance in Staphylococcus aureus: A review. J. clin. Path., 26:899-913.

22. Sabet N. S., Subramaniam G., Navaratnam P., Sekaran S. D. (2007). Detection of mecA and ermA genes and simultaneous identification of Staphylococcus aureus using triplex real-time PCR from Malaysian S. aureus strain collections. International Journal of Antimicrobial Agents, 29:582-585.

23. Mcdougal L. K. and Thornsberry C.(1986). The Role of 13-Lactamase in Staphylococcal Resistance to Penicillinase-Resistant Penicillins and Cephalosporins. Journal of Clinical Microbiology, 23(5):832-839.

24. Bergeron M. G. and Ouellette M. (1998). Preventing Antibiotic Resistance through Rapid Genotypic Identification of Bacteria and of Their Antibiotic Resistance Genes in the Clinical Microbiology Laboratory. Journal of Clinical Microbiology, 36(8): 2169-2172. 